\title{
Poor inter-rater reliability on mock anesthesia oral examinations
}

\section{[Le pauvre coefficient d'objectivité d'examens oraux en anesthésie simulés]}

Eric Jacobsohn MBCHB MHPE FrCPC, ${ }^{*}$ P. Alan Klock MD $†$ Michael Avidan MBBCH, ${ }^{*}$ and the Oral Examinations Group ${ }^{\ddagger}$

Purpose: Inter-rater reliability (IRR) and communication skills are both important factors that have been shown to affect oral examination scores. This study was designed to test: I) IRR of a group of American Board of Anesthesiology (ABA) and the Royal College of Physicians and Surgeons of Canada (RCPSC) graders who graded in true isolation; 2) the effect of teaching residents examination techniques.

Methods: This was a randomized, pretest-posttest trial. Twenty-five residents did an initial oral examination (EI) resembling the ABA examination. They were then randomized into two groups, a routine education group, and an intervention group that was taught oral examination skills. Six weeks later they did another oral examination (E2). The videotaped examinations were subsequently scored by six experienced RCPSC and ABA graders.

Results: There was very poor IRR on EI (weighted Kappa = 0.166 , intraclass correlation coefficient 0.243 ), which improved only slightly on E2 (weighted Kappa $=0.275, P=N S$; intraclass correlation coefficient $=0.405, P<0.0 \mathrm{I})$. Pass rate for graderpairs increased from EI to E2 (I5\% vs $43 \%, P=0.01$ ). The improved pass rate on E2 occurred in both the routine education group and in the intervention group. There was no significant difference between RCPSC and ABA graders. Teaching examination skills per se did not improve performance, but this conclusion may be limited by the poor IRR. Practice orals do appear to improve performance on future examinations.

Conclusions: Inter-rater reliability may be poor when graders score an oral examination in true isolation. Teaching candidates an oral examination communication and presentation technique did not appear to improve performance. Oral examination practice may be of value in training for future examinations.
Objectif : Le coefficient d'objectivité (CO) et les habiletés de communication sont deux facteurs importants qui modifient les scores de l'examen oral. Notre étude voulait tester : I) le CO d'un groupe d'examinateurs de l'American Board of Anesthesiology (ABA) et du Collège royal des médecins et chirurgiens du Canada (CRMCC) qui travaillent en isolement complet; 2) l'effet de l'enseignement de techniques d'examen aux résidents.

Méthode : L'essai randomisé comportait un prétest et un posttest. Vingt-cinq résidents ont passé un premier examen oral (EI) comme celui de l'ABA. Puis, ils ont été répartis en un groupe de formation courante, et un groupe d'intervention à qui on a présenté des techniques d'examen oral. Six semaines plus tard, ils ont passé un autre examen (E2). Les examens enregistrés sur bande vidéo ont été cotés ensuite par six examinateurs expérimentés du CRMCC et de I'ABA.

Résultats : Le CO était très pauvre à l'El (Kappa pondéré = 0,166 , coefficient de corrélation intraclasse de 0,243) et s'est amélioré légèrement à l'E2 (Kappa pondéré $=0,275, P=N S$; le coefficient de corrélation intraclasse $=0,405, P<0,0$ I). Le taux de réussite pour les paires d'examinateurs a augmenté de $E I$ à E2 $(15 \%$ vs $43 \%, P=0,01)$. Cette amélioration est survenue dans les deux groupes, de formation courante et d'intervention. II n'y avait pas de différence significative entre les examinateurs du CRMCC et de I'ABA. L'enseignement de techniques d'examen n'a pas amélioré en soi la performance, ce qui a pu être limitée par le pauvre CO. La pratique d'examens oraux semble bien améliorer la performance aux examens ultérieurs.

Conclusion : Le coefficient d'objectivité peut être pauvre quand les examinateurs cotent un examen oral en isolement complet. L'enseignement de technique de communication et la présentation d'examen oral aux candidats ne semblent pas améliorer la performance. Mais la pratique d'examen oral pourrait avoir de la valeur dans la formation aux futurs examens.

From the Departments of Anesthesiology and Surgery, ${ }^{*}$ Washington University School of Medicine, St. Louis, MO; and the Anesthesia and Critical Care, $\nmid$ University of Chicago, Chicago, Illinois, USA; (see Appendix II). $\ddagger$

Address correspondence to: Dr. Eric Jacobsohn, Department of Anesthesiology, Washington University School of Medicine, $660 \mathrm{~S}$

Euclid, MC 8054, St. Louis, MO 63110, USA. Phone: 314-747-4155; Fax: 314-362-4551; E-mail: [acobsoe@msnotes.wustl.edu

Funding was provided by the Royal College of Physicians and Surgeons of Canada (Medical Education Fellowship to E.J.), the Section of Critical Care Research Fund, University of Manitoba (E.J.), and the Department of Anesthesia and Critical Care Research Trust,

University of Chicago (E.J., P.A.K.).

Accepted for publication January 19, 2006.

Revision accepted January 30. 2006.

Competing interests: None declared.

This article is accompanied by an editorial. Please see Can J Anesth 2006; 53: 639-42. 


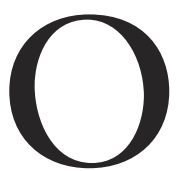

RAL examinations remain an integral part of the certifying process in many countries, including Canada and the United States. The stated goals of both the Royal College of Physicians and Surgeons of Canada (RCPSC) and the American Board of Anesthesiology $(\mathrm{ABA})$ oral examinations are similar, and these goals aim to test judgment, application of knowledge, adaptability, clarity of expression, and ability to communicate effectively. Many factors have been shown to affect the score in oral examinations, including the validity and inter-rater reliability (IRR) of the examination ${ }^{1-4}$ as well as several examinee factors. With regard to IRR, in two studies of mock anesthesia oral examinations, one resembling the ABA and one resembling the RCPSC examination, the IRR was reported as being acceptable. ${ }^{2,3}$ With regard to examinee factors, a study of surgery residents demonstrated that a candidate's communication style may be a significant factor in his/her overall score. ${ }^{5}$ It is therefore possible that some candidates may fail oral examinations due to problems with IRR and/or because they are unable to communicate effectively.

There were two primary aims of this study: 1) to test the IRR of experienced oral examiners who had previously examined at the ABA or RCPSC; 2 ) to test the effect of teaching candidates certain oral examination skills, such as presentation and communication techniques. The secondary aim was to compare scores given by graders from the ABA and RCPSC.

\section{Methods}

After approval from the Institutional Review Board, 29 anesthesiology residents in the University of Chicago Department of Anesthesia and Critical Care residency program were sent recruitment letters inviting them to participate in the study. The study was a randomized, two-treatment group pretest posttest trial (Figure). Twenty-seven residents in years one to three of clinical anesthesia training (CA-1 to CA-3) participated and were paid a $\$ 50$ stipend. Due to scheduling difficulties, two withdrew.

All of the residents were sent the oral examination information package distributed by the $\mathrm{ABA}$, which includes a section on pitfalls in taking oral examinations. The residents then did an oral examination (pretest, examination E1) similar to session $\mathrm{B}$ of the ABA exam. After being given one of two stem questions ( $\mathrm{SCl}$ and $\mathrm{SC} 2$ ) and ten minutes of preparation, the candidate was questioned for 20 min on preoperative and intraoperative scenarios. After the stem, there was a ten minute period of questioning on one of two additional short-cases (ACl and AC2, Appendix
1). The scenarios that were used had previously been used at a "real" ABA exam. These scenarios were assessed by the principal investigator (E.J.), the examiner (P.A.K.), and two other senior anesthesiologists who were active ABA examiners and the scenarios were deemed to be fair and of comparable difficulty. During the questioning portion of the examination one person (P.A.K.), who was blinded to the resident's group assignment, examined all residents and used a grid to guide his questioning. All the examinations were videotaped. The residents were all similarly dressed in a white coat, were given a numerical code for identification, and could not be identified by name on the videotapes.

After El, the residents were randomized and stratified by year of training to one of two groups: Group $\mathrm{T}$ (new educational intervention, $n=13$ ) and Group $\mathrm{R}$ (routine residency education, $n=14$ ). The residents in Group T received a package relating to oral examination presentation and communication techniques. This package included the information that was to be presented at a communication skills workshop they were required to attend. This workshop was designed to improve the resident's oral examination communication and presentation skills. It consisted of a presentation on the structure and pitfalls in the oral examinations, a review of the ABA scoring system, a review of the information that the $\mathrm{ABA}$ sends to oral examination candidates (which includes reviewing a typical examination scenario and the accompanying examiner's grid), and a discussion on oral examination communication techniques such as clarity and speed of speaking, intonation, eye contact, body language, and dress. This workshop also taught the participants a comprehensive system to present and communicate cases on an oral examination. After the workshop, the participants were divided into small groups to practice the presentation and communication system. They were urged to start using the system in their daily practice when communicating or presenting cases to their attending physicians. To reinforce learning the system, individual one-hour follow-up sessions were held with Group T. Group T continued to attend all the usual residency educational seminars. Group $\mathrm{R}$ did not attend the educational intervention, but continued their usual residency educational and reading schedules. The residents agreed not to communicate about the examination content. They understood that there was no gain or loss from a good or bad performance and they acknowledged that after accepting a stipend it would be unethical if they did communicate with each other along with invalidating the study. Six weeks after the workshop, the residents in both 


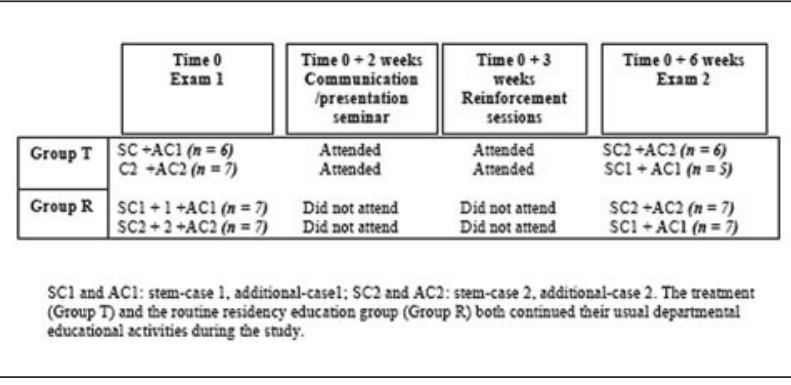

FIGURE The study design.

groups did another oral examination (posttest, E2). The same questions used in El were administered, but in crossover design (Figure).

The videotaped performances were randomly copied to a series of videotapes. They were "scrambled" as to the sequence of candidates and to El or E2; this was done to minimize the confounding variable of grader calibration. The series of videotapes were then sent to the six oral examination graders, three with current experience examining for the ABA, and three with current or very recent experience examining for the RCPSC. These graders had been selected on the basis of peer examiners (at the ABA and RCPSC) recommendations as neither being too difficult nor too lenient. The graders were paid for their time and knew nothing of study design. The graders used a scoring sheet similar to that used by the ABA that has an ordinal scale of $70,73,77$, and 80 (Supplement 1: Scoring sheet A, available as Additional Material at www.cja-jca.org). In addition to the scoring sheet, to further try and standardize scoring graders were given an educational module regarding scoring of oral examinations (which included the information that the $\mathrm{ABA}$ examiners are given regarding the $\mathrm{ABA}$ oral examination). They also received an examiners' grid for each question that listed the topics that had to be addressed in the question. A candidate passed if the average score given by two graders was $>75$. To collect more detailed data that could not be assessed by the ABA scoring system, the investigators designed another scoring sheet that included an overall percentage score (0-100) and several ten-point ordinal scores (Supplement 2: Scoring sheet B, available as Additional Material at www.cja-jca.org).

After E1 and E2, the residents completed several self-assessment questionnaires, including one for fairness, difficulty, examiner intimidation and self-assessment score. An anonymous questionnaire after E2 was used to detect if there was any communication between residents about the examination.

\section{Statistical analysis}

Data were analyzed using the Statistical Analysis System (SAS 6.12, Cary, NC, USA) with assistance from the Biostatistics Department of the University of Manitoba. Unpaired t tests were used to compare normally distributed characteristics between the groups, and paired $t$ tests were used to compare normally distributed characteristics within the groups. McNemar test was used to assess changes between proportions within the groups. Repeated measures ANOVA were used to compare the effect of the intervention on grader and self-assessment scores. For all these statistical tests, $\alpha$ was set at 0.05 . Intraclass correlation coefficients (ICC) were used to calculate IRR between the graders for interval scores. Weighted Kappa tests were used for agreement between two methods, raters, or observers, when the observations are measured on an ordinal scale. The degree of agreement is indicated by the weighed Kappa statistic, which can be roughly interpreted as follows: $0=$ trivial; $0.1=$ small; moderate $=0.3$; large $=0.5$; very large $=0.7$; nearly perfect $=0.9$.

\section{Results}

On the resident questionnaires (Table I), there was no reported communication between residents, no intimidation by the examiner, and the examinations were rated as being fair and meeting the stated goals. There was no significant difference between difficulty of El or $\mathrm{E} 2$, or between the two question formats $(\mathrm{SCl}+$ $\mathrm{ACl}$ and SC2 + AC2). On the grader's questionnaire (Table II), the graders rated the examinations as fair, of comparable difficulty to each other, and to a "real" certifying examination at their respective boards.

Inter-rater reliability using ICC for the component and overall percentage scores, as well as the weighted Kappa coefficient for ordinal scores, are shown in Table III. On examination El, ICC was generally poor, ranging from 0.113 [95\% confidence interval (CI) $0.0 .-0.305]$ to 0.283 (95\% CI $0.087-0.497$ ) for the component scores, and from $0.175(95 \%$ CI $0.0135-0.378)$ to 0.182 (95\% CI $0-0.415$ ) for the overall percentage score. There was a significant improvement in the ICC for the overall percentage and component scores from examination E1 to E2, but ICC remained generally poor. The weighted Kappa for the ordinal scores ranged from 0.01 (95\% CI $-0.27-0.28)$ to 0.32 (95\% CI -0.02-0.66) on El, and from $0.16(95 \% \mathrm{CI}-0.16-0.48)$ to 0.5 (95\% CI $0.25-0.74)$ on E2. Unlike the percentage scores, there was not a significant increase from E1 to E2.

There was a significant improvement in the pass rate from E1 to E2 for all RCPSC and ABA graders 
TABLE I Residents' questionnaire

\begin{tabular}{|c|c|c|c|}
\hline & Group $R n=14$ & Group $T n=11$ & $P$ \\
\hline Did you communicate about the examinations to any other resident? & 0 & 0 & \\
\hline Do you have a method for presenting clinical cases during an examination? (\% yes) & 42.9 & 72.7 & 0.49 \\
\hline Have you ever taken a training course that teaches oral exam skills? (\% yes) & 0 & 0 & \\
\hline $\begin{array}{l}\text { Should a communication system for oral examinations be taught during residency } \\
\text { education? }(1=\text { strongly disagree; } 10=\text { strongly agree })\end{array}$ & $8.5 \pm 0.9$ & $9.0 \pm 1.8$ & 0.79 \\
\hline $\begin{array}{l}\text { Should a system to present daily clinical cases be taught during residency training? } \\
(1=\text { strongly disagree; } 10=\text { strongly agree })\end{array}$ & $8.6 \pm 1.1$ & $9.0 \pm 1.8$ & 0.91 \\
\hline $\begin{array}{l}\text { How good are the current reference texts at teaching presentation and organization } \\
\text { for anesthesia cases? }(1=\text { poor; } 10=\text { excellent })\end{array}$ & $5.1 \pm 1.5$ & $5.1 \pm 1.8$ & 0.96 \\
\hline Was the seminar a worthwhile experience? $(1=$ not at all; $10=$ very much $)$ & $\mathrm{N} / \mathrm{A}$ & $9.0 \pm 0.9$ & \\
\hline $\begin{array}{l}\text { Will the information learned in the seminar help you in the future? } \\
(1=\text { not at all; } 10=\text { very much) }\end{array}$ & $\mathrm{N} / \mathrm{A}$ & $8.7 \pm 1.3$ & \\
\hline $\begin{array}{l}\text { Did the system help you prepare and organize your case in the } 10 \text {-minute } \\
\text { preparation time? ( } 1=\text { not at all; } 10=\text { very much })\end{array}$ & $\mathrm{N} / \mathrm{A}$ & $8.8 \pm 1.0$ & \\
\hline $\begin{array}{l}\text { Did the system make you feel more organized when presenting? } \\
(1=\text { not at all; } 10=\text { very much) }\end{array}$ & $\mathrm{N} / \mathrm{A}$ & $8.9 \pm 1.1$ & \\
\hline $\begin{array}{l}\text { Does the system help you organize clinical cases in daily practice? } \\
(1=\text { not at all; } 10=\text { very much) }\end{array}$ & $\mathrm{N} / \mathrm{A}$ & $8.3 \pm 1.0$ & \\
\hline Will you continue using the system in practice? (\% yes) & $\mathrm{N} / \mathrm{A}$ & 90 & \\
\hline Will you continue using the system in oral examinations? (\% yes) & $\mathrm{N} / \mathrm{A}$ & 100 & \\
\hline
\end{tabular}

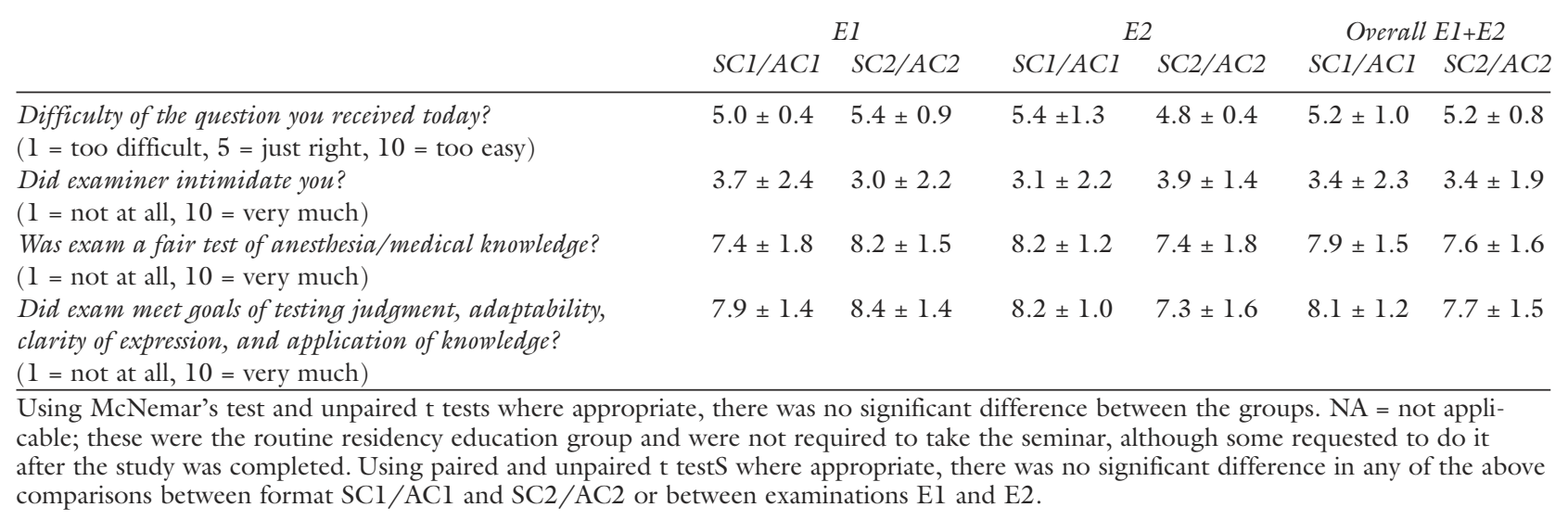

(Table IV). The average single RCPSC grader's pass rate of $28 \%$ on El was lower than the average single ABA grader rate of $44 \%(P=0.05)$, but this difference was not significant if the most lenient $\mathrm{ABA}$ grader (US1) and most stringent RCPSC grader (Can3) were omitted (RCPSC $34 \%$ vs US $24 \%, P=0.28$ ). The average single RCPSC and ABA graders' pass rate were identical on E2. The mean pass rate for all single examiners improved from $36 \%$ on $\mathrm{E} 1$ to $64 \%$ on E2 ( $P$ $<0.01)$. The average RCPSC and ABA pairs pass rate was identical on E2. The overall pairs pass rate for all graders increased from $15 \%$ on E1 to $43 \%$ on E2 ( $P$ $<0.01)$. Using the ordinal system, $44 \%$ of candidates would have failed irrespective of the grader, but only $8 \%$ of candidates passed irrespective of the grader. In the remaining $48 \%$ of candidates the chance of pass- ing or failing was examiner dependent. In the most extreme case one resident received a score of 80 (clear pass) from four graders, and a score of 70 (clear fail) from two graders.

In Table $\mathrm{V}$, we show the effect of the teaching intervention and the effect of a repeat examination on scores. Although residents in both Groups $\mathrm{R}$ and $\mathrm{T}$ had a significant improvement from E1 to E2 on all the component and overall scores, but there were no significant differences in the improvement between the groups. The group-time effect shows that there is no significant difference in the degree of improvement in scores between the Groups R and T, and the group effect shows that they were not significantly different from each other at any time point. 
TABLE II Graders' evaluation of the examination process

\begin{tabular}{|c|c|c|c|c|}
\hline & & $\begin{array}{l}\text { Rate the difficulty of } \\
\text { this exam compared } \\
\text { to others in the study } \\
\text { ( } 1=\text { much more difficult, } \\
5 \text { = same, } 10=\text { much easier) }\end{array}$ & $\begin{array}{l}\text { Rate the difficulty of } \\
\text { this exam compared to } \\
\text { real } A B A \text { examinations } \\
(1=\text { too difficult, } 5=\text { acceptable, } \\
10=\text { too easy })\end{array}$ & $\begin{array}{l}\text { Was the examiner fair? } \\
(1=\text { not fair, } 10=\text { fair })\end{array}$ \\
\hline Grader 1 & El & $5.3 \pm 3.2$ & $6.0 \pm 1.9$ & $7.0 \pm 2.1$ \\
\hline $\mathrm{ABA}$ & E2 & $5.6 \pm 2.0$ & $6.3 \pm 1.7$ & $6.6 \pm 2.0$ \\
\hline Grader 2 & El & $5.0 \pm 0.0$ & $5.0 \pm 0.0$ & $4.6 \pm 0.8$ \\
\hline $\mathrm{ABA}$ & E2 & $5.0 \pm 0.2$ & $5.0 \pm 0.2$ & $4.3 \pm 1.1$ \\
\hline Grader 3 & El & $4.9 \pm 0.9$ & $6.8 \pm 0.7$ & $5.6 \pm 2.7$ \\
\hline $\mathrm{ABA}$ & $\mathrm{E} 2$ & $5.0 \pm 1.0$ & $6.9 \pm 0.6$ & $6.4 \pm 2.4$ \\
\hline Grader 4 & $\mathrm{El}$ & $5.0 \pm 1.5$ & $5.7 \pm 0.7$ & $5.4 \pm 1.3$ \\
\hline RCPSC & E2 & $5.1 \pm 1.5$ & $5.7 \pm 0.8$ & $5.3 \pm 1.4$ \\
\hline Grader 5 & El & $5.0 \pm 0.5$ & $6.8 \pm 0.6$ & $8.3 \pm 1.5$ \\
\hline RCPSC & E2 & $5.0 \pm 0.2$ & $6.8 \pm 0.5$ & $8.7 \pm 1.7$ \\
\hline Grader 6 & El & $4.5 \pm 1.0$ & $5.2 \pm 0.4$ & $8.1 \pm 1.6$ \\
\hline RCPSC & $\mathrm{E} 2$ & $4.8 \pm 1.1$ & $5.1 \pm 0.3$ & $8.2 \pm 0.8$ \\
\hline \multirow[t]{2}{*}{ All graders } & El & $5.0 \pm 1.2$ & $5.9 \pm 1.2$ & $6.5 \pm 2.2$ \\
\hline & E2 & $5.0 \pm 1.2$ & $6.0 \pm 1.2$ & $6.6 \pm 2.1$ \\
\hline
\end{tabular}

$\mathrm{ABA}=$ American Board of Anesthesiology; RCPSC $=$ Royal College of Physicians and Surgeons of Canada; ${ }^{\mathrm{a}}$ Using paired $\mathrm{t}$ tests, there was no significant difference between E1 and E2 in any of the categories.

TABLE III Inter-rater reliability: Intraclass correlation coefficients (ICC, with 95\% CI) for the component scores and overall percentage score, and weighted Kappa coefficients for the overall ordinal score

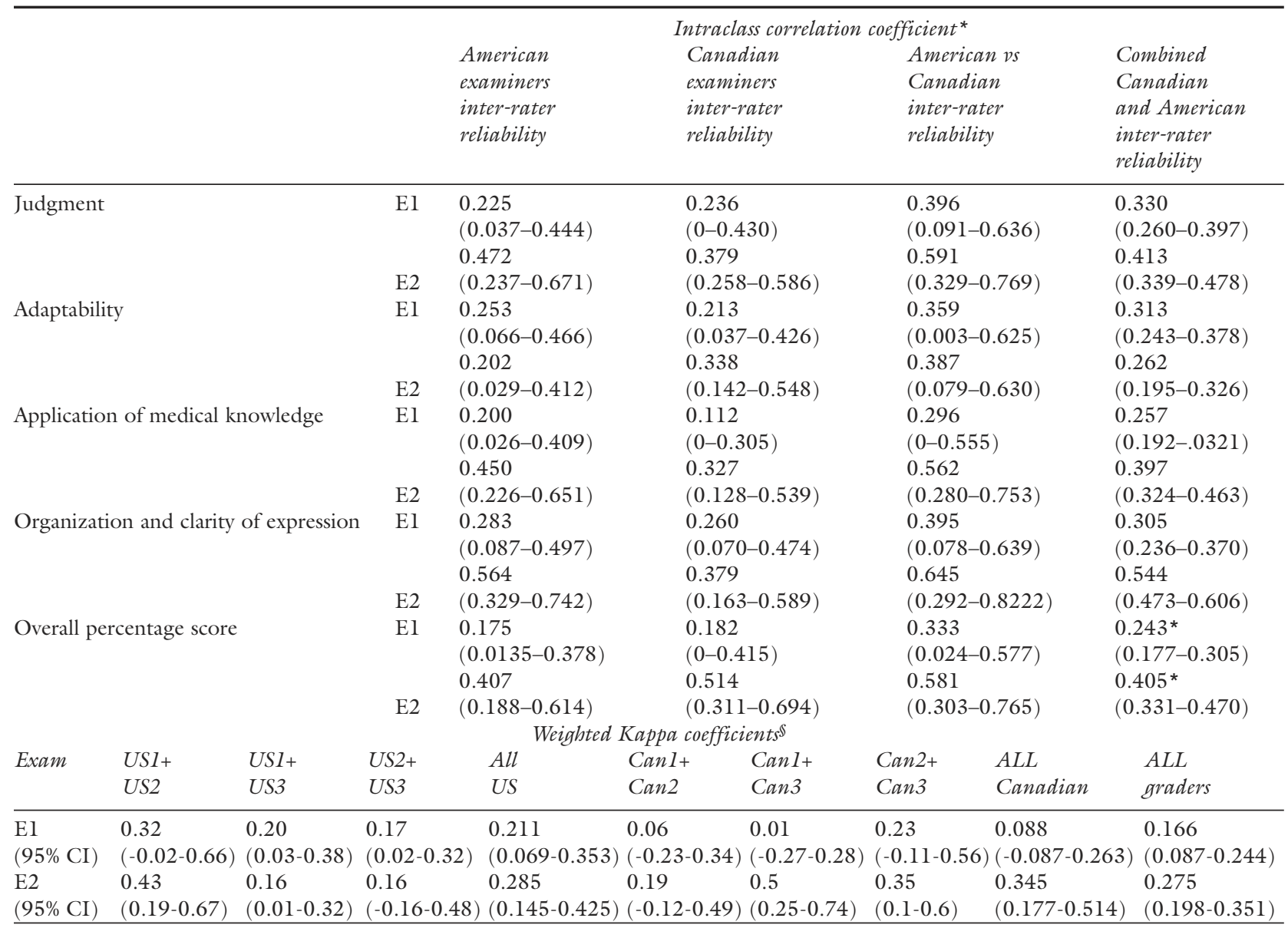

$\mathrm{CI}=$ confidence interval. *There was a significant improvement in intraclass correlation coefficient from E1 to E2 for the overall percentage score $(P<0.01)$. ${ }^{\$}$ There was no significant improvement in weighted Kappa from E1 to E2. 
TABLE IV Pass rates (\%) with one and two graders

\begin{tabular}{|c|c|c|c|}
\hline \multirow[b]{2}{*}{ Grader } & \multicolumn{3}{|c|}{ One grader } \\
\hline & E1 & $E 2$ & $P$ \\
\hline USI & 80 & 88 & NS \\
\hline US2 & 24 & 48 & 0.03 \\
\hline US3 & 24 & 44 & 0.05 \\
\hline Average US* & 44 & 60 & 0.04 \\
\hline Canl & 44 & 60 & 0.05 \\
\hline Can2 & 24 & 72 & 0.001 \\
\hline Can3 & 16 & 48 & 0.01 \\
\hline Average Can ${ }^{*}$ & 28 & 60 & 0.01 \\
\hline \multirow[t]{3}{*}{ US + Can pass rate } & 36 & 64 & 0.02 \\
\hline & \multicolumn{3}{|c|}{ Two graders } \\
\hline & El & $\mathrm{E} 2$ & $P$ \\
\hline US1 + US2 & 12 & 36 & 0.03 \\
\hline US1 + US3 & 24 & 44 & 0.04 \\
\hline US2 + US3 & 28 & 48 & 0.04 \\
\hline All US pairs pass rate ${ }^{*}$ & 22 & 43 & 0.01 \\
\hline Can $1+\operatorname{Can} 2$ & 12 & 44 & 0.01 \\
\hline Can $1+\operatorname{Can} 3$ & 8 & 44 & 0.01 \\
\hline $\operatorname{Can} 2+\operatorname{Can} 3$ & 8 & 40 & 0.01 \\
\hline All Can pairs & & & \\
\hline pass rate ${ }^{*}$ & 9 & 43 & 0.001 \\
\hline All Can + US pairs & & & \\
\hline pass rate & 15 & 43 & 0.01 \\
\hline
\end{tabular}

NS = not significant. McNemar's test was used to compare El with E2 and to compare the average US and Canadian pass rates. ${ }^{*} P=0.05$ for average American vs Canadian pass rate for examination $\mathrm{E} 1$, and $P=1$ for examination E2.

\section{Discussion}

The results of this study show that: 1) IRR between experienced oral examiners, when grading in true isolation, was poor. The IRR improved only modestly on a repeat oral examination; 2) teaching an oral examination presentation and communication techniques did not improve scores, but that a repeat oral examination had a powerful effect at improving performance; 3 ) graders from the RCPSC and ABA gave similar scores.

The IRR of graders scoring in true isolation (i.e., videotaped performances) was very poor on both examinations. Although some improvement was noted on the second examination, the IRR never reached an acceptable level, that is, $>0.7$. Most certifying boards strive for IRR levels of 0.8 to 0.9 . In a four-year prospective study of anesthesiology residents, 441 practice oral examinations resembling the $\mathrm{ABA}$ exam were administered to 190 residents. ${ }^{2}$ Using the ABA ordinal score and pairs of examiners, the IRR was found to be 0.68 . However, in this study, the examin- ers were faculty members in the residency program and therefore knew the residents. ${ }^{2}$ This fact could have lead to examiner bias due to the "halo effect" where a candidate is scored high or low based upon previous encounters or knowledge of the resident. In a study of practice oral examinations using the RCPSC oral examination format, the mean IRR ranged from 0.477 to 0.791 (measured at two different study sites and at two different times). ${ }^{3}$ However, the examiners were not truly grading in isolation, and not all examiners were experienced RCPSC examiners.

There are several possible explanations for the poor IRR in our study. Examiners were evaluating residentsin-training who were probably not as well prepared as true candidates. Given that IRR is weaker for poor performances than good performances, we may have expected poorer IRR for the practice orals than for real certifying examinations. This may be supported by the observation that the scores improved significantly from E1 to E2. This was accompanied by an improvement in the IRR for the component scores, the overall continuous score, and the ordinal score. It may be that if the residents had been in their CA3 years that the IRR would have been better. We did not attempt a subgroup analysis for the CA3 residents because the group was too small. Another possible explanation for the poor IRR may be that the examinations were inconsistent for content and quality. However, this is unlikely, as each question had previously been used at an $\mathrm{ABA}$ certifying exam, and the graders felt that they were fair and similar to a certifying ABA examination. Also, the examiner (P.A.K.) had been on faculty for five years, was trained in administering oral examinations, and had developed the grid himself.

A plausible explanation for the poor IRR may be that conscious or subconscious consensus building between graders was not possible due to the study design. In 1966, it was first suggested that "subtle communication" occurred between examiners. ${ }^{6}$ The graders in our study scored the examinations without being aware of the study aims, and there was no possibility for consensus building. Most exam boards report good IRR, and in the two practice oral examination studies ${ }^{2,3}$ the IRR was reported as being fair to good. However, graders were invariably not scoring in true isolation, and non-verbal communication could have occurred.

Another factor that may have affected the IRR is the type of grader; it is well known that there are strict and lenient graders. It appears that one of the US graders (USI) was lenient, and one of the Canadian examiners (Can3) was strict. This exposes one of the difficulties with oral examinations, namely that they 
TABLE $\mathrm{V}$ The effect of the teaching intervention per se and the effect of oral examination practice (i.e., the repeat examination) on the component and overall scores

\begin{tabular}{|c|c|c|c|c|c|c|c|c|}
\hline & & $\begin{array}{l}\text { Group } R \\
n=14 \\
E 1\end{array}$ & $E 2$ & $\begin{array}{l}\text { Group T } \\
n=11 \\
E 1\end{array}$ & $E 2$ & $\begin{array}{l}\text { Time } \\
\text { (pre/post) } \\
P\end{array}$ & $\begin{array}{l}\text { Group-time } \\
P\end{array}$ & $\begin{array}{l}\text { Group } \\
P\end{array}$ \\
\hline Judgment & Can & $4.0 \pm 1.9$ & $5.3 \pm 2.0$ & $4.2 \pm 1.8$ & $5.0 \pm 1.7$ & 0.0003 & 0.42 & 0.78 \\
\hline \multirow[t]{2}{*}{$(1=$ poor $; 10=$ excellent $)$} & US & $4.9 \pm 2.1$ & $5.7 \pm 2.4$ & $5.0 \pm 2.5$ & $5.8 \pm 2.2$ & 0.004 & 0.99 & 0.93 \\
\hline & All & $4.5 \pm 2.0$ & $5.5 \pm 2.2$ & $4.6 \pm 2.2$ & $5.4 \pm 1.9$ & 0.0002 & 0.56 & 0.93 \\
\hline Adaptability & Can & $4.0 \pm 1.0$ & $5.2 \pm 2.0$ & $4.7 \pm 1.5$ & $5.8 \pm 1.7$ & 0.0001 & 0.99 & 0.24 \\
\hline \multirow[t]{2}{*}{$(1=$ poor; $10=$ excellent $)$} & US & $5.2 \pm 2.0$ & $5.9 \pm 2.2$ & $4.9 \pm 2.4$ & $5.9 \pm 2.1$ & 0.002 & 0.71 & 0.72 \\
\hline & All & $4.6 \pm 1.5$ & $5.6 \pm 2.1$ & $4.8 \pm 1.9$ & $5.9 \pm 1.9$ & 0.0001 & 0.78 & 0.35 \\
\hline Application medical & Can & $4.0 \pm 1.7$ & $5.4 \pm 2.1$ & $4.0 \pm 2.0$ & $4.8 \pm 2.0$ & 0.0001 & 0.27 & 0.49 \\
\hline Knowledge & US & $5.0 \pm 2.3$ & $6.0 \pm 2.3$ & $5.1 \pm 2.4$ & $5.6 \pm 2.4$ & 0.0086 & 0.43 & 0.77 \\
\hline$(1=$ poor $; 10=$ excellent $)$ & All & $4.5 \pm 2.0$ & $5.7 \pm 2.2$ & $4.5 \pm 2.2$ & $5.2 \pm 2.2$ & 0.0003 & 0.19 & 0.52 \\
\hline Presentation and & Can & $3.8 \pm 1.6$ & $4.9 \pm 2.3$ & $3.9 \pm 1.9$ & $4.8 \pm 1.7$ & 0.0001 & 0.71 & 0.95 \\
\hline Organizational skills & US & $4.6 \pm 2.2$ & $6.1 \pm 2.5$ & $4.9 \pm 2.3$ & $5.5 \pm 2.6$ & 0.0003 & 0.08 & 0.73 \\
\hline$(1=$ poor $; 10=$ excellent $)$ & All & $4.2 \pm 1.9$ & $5.5 \pm 2.4$ & $4.4 \pm 2.1$ & $5.1 \pm 2.1$ & 0.0001 & 0.12 & 0.82 \\
\hline \multirow[t]{3}{*}{ Overall \% score } & Can & $70.8 \pm 5.5$ & $75.5 \pm 7.2$ & $70.2 \pm 7.4$ & $73.8 \pm 6.1$ & 0.0001 & 0.26 & 0.48 \\
\hline & US & $73.8 \pm 8.2$ & $77.6 \pm 8.6$ & $73.8 \pm 9.4$ & $77.0 \pm 8.9$ & 0.0006 & 0.76 & 0.86 \\
\hline & All & $72.3 \pm 6.8$ & $76.5 \pm 7.9$ & $72.0 \pm 8.4$ & $75.4 \pm 7.5$ & 0.0001 & 0.32 & 0.59 \\
\hline$\%$ of residents that & Can & 28.6 & 57.1 & 27.3 & 63.6 & 0.0001 & 0.11 & 0.99 \\
\hline received a passing & US & 45.7 & 61.9 & 42.4 & 57.6 & 0.019 & 0.82 & 0.66 \\
\hline grade $(>75 \%)$ & All & 36.2 & 59.5 & 34.8 & 60.6 & 0.0001 & 0.35 & 0.75 \\
\hline
\end{tabular}

are difficult to grade reliably even when they have been standardized. Standardizing the oral and having examiner grids and scoring sheets helps, but it does not eliminate this problem. In our study, when using the ordinal score, $44 \%$ of candidates failed irrespective of grader, and only $8 \%$ passed irrespective of grader. In the remaining $48 \%$, the chance of passing or failing was examiner dependent. In order to minimize the IRR problems, many examining boards provide training for examiners and have ongoing monitoring of their examiners. The graders in our study were all trained and experienced in giving oral examinations. Another possible way to try and improve the process would be for the same examiners to ask the same question to all candidates, that is, have the candidates move from one room to another during their exam. ${ }^{3}$ This would mean that the examiners in the same room would ask only one question to multiple candidates. This would have the effect of standardizing the exam as well as assuring some degree of standardization in the scoring. This makes the examination logistically more challenging, especially for large numbers of candidates.

We thought that comparing RCPSC and ABA graders would be interesting as both countries have high standards in anesthesiology training, similar certification processes, and the competencies expected of a certified anesthesiologist are very similar. ${ }^{7}$ However, the analysis was complicated by the variability in grader stringency. One ABA grader was lenient (pass rate $80 \%$ ), and one RCPSC grader was strict (pass rate $16 \%$ ). When these two were removed from the analysis, there was no significant difference in the pass rates between the ABA and RCPSC graders. When the variability of the grader pass rates is considered, we would have needed 25 residents per group and 12 graders per country to detect a $10 \%$ difference in pass rates with a power of $80 \%$.

The improved scores from the first to the second examination may have several possible explanations. Both groups reported significantly less anxiety at the time of the second examination. This is an important finding as it has been shown that less confident and more anxious examinees do worse. ${ }^{8}$ Anesthesiology residents who were exposed to repeat mock oral examinations became more confident on subsequent examinations, even though their anxiety remained unchanged. ${ }^{9}$ We speculate that the residents in our study probably felt less anxious on the second examination as they knew that the examiner (P.A.K.) was non-intimidating and fair (based on their experience on El). The combination of less anxiety and improved confidence could partly explain the improvement in the graders' scores. The intervening time was only six weeks, making it unlikely that the improvement could be attributed to maturation in knowledge. The fact that both groups improved suggests that a repeat oral examination may have a powerful effect on examination performance. Practice orals in anesthesiology are 
well established and have been proposed to enhance exam-taking skills.

One of the primary goals of this study was to establish whether a presentation and communication method could improve performance. We could not show this. It is unlikely that inadequate dosage (strength of intervention) occurred; the seminar and follow-up sessions were comprehensive. The intervention may have been ineffective if the residents were not motivated to use it, but the questionnaire suggests that residents liked the system and used it. Another possible explanation may be that the poor IRR may have made it difficult for the effect of the intervention to be seen, especially when there was such a powerful effect of a repeat oral examination. A reassuring explanation may be that experienced graders were not swayed by elegant communication and presentation skills in the absence of a substantive knowledge base. While it was once believed that communication skills were a discrete component in assessing clinical competence, it is now accepted that communication skills are dependent on the context in which they are performed. ${ }^{10}$ Using standardized patients, Colliver $e t$ al. showed that clinical competence and communication skills were related only in the clinical context in which they were presented. ${ }^{11}$ In their work, if students did badly in the clinical context, communication would be rated poorly. Since most of the residents in our study did not receive overall passing grades, the association between poor overall competences may have been another factor in addition to the poor IRR. The sample population consisted of residents in their CAl-CA3 years, and it may be that if we studied only residents with a more developed knowledge (CA3) that we would have shown an effect. Another possible explanation for not showing a difference between groups may be that the method we taught was simply not good enough.

The study has several limitations. The residents were a "convenience" sample and included residents from CAl-CA3 years. Junior residents were unlikely to do well, and it can be assumed that their performance would be below that of candidates presenting themselves for a certifying examination. The IRR of poor performances is less reliable than that of good performances. ${ }^{11}$ The IRR results of the study may therefore have been biased by the participation of the junior residents. However, potentially incompetent candidates do sometimes present themselves for certifying examinations, and it would be concerning if some of them passed. Another limitation of the study was in the examiner's grid. Although the questions were standardized, each examination could take a slightly different course depending on how the resident responded. This could have made the scoring on the grid difficult to follow at times. However, this again is something that does occur in certifying examinations. Another weakness is that the self-assessment scores may have significant bias. The investigator had the ability to identify the residents, and hence they may have been less likely to criticize the intervention.

In conclusion, we have shown that on a mock anesthesiology oral examination resembling session $\mathrm{B}$ of the ABA certifying examination, that: I) IRR between experienced examiners was poor when they graded in isolation, and many candidates would have passed or failed depending on the examiner; 2) practice oral examinations have a powerful effect on improving performance by reducing candidate anxiety and improving confidence; 3 ) oral examination presentation and communication skills per se did not improve scores; and 4) graders from the ABA and RCPSC appeared to give similar scores.

\section{Acknowledgement}

We sincerely thank Ms. Mary Cheang, Biostatistician, University of Manitoba, for her expert advice and assistance in doing the analyses.

\section{APPENDIX I: Examination cases and examiner's grids}

Stem case 1 (SCl): resident worksheet

A 68-yr-old male with steroid-dependent rheumatoid arthritis is scheduled for a revision total hip replacement. He has diabetes, a hiatal hernia, and coronary artery disease. He had a myocardial infarction in the past which was complicated by congestive heart failure. Medications include: digoxin, furosemide, captopril, atenolol, prednisone, ranitidine and glyburide. Vital signs: P 59, BP 130/70, R 14, T 36.9.

\section{SCl: examiner's grid}

A 68-yr-old male with steroid-dependent rheumatoid arthritis is scheduled for a revision total hip replacement. He has diabetes, a hiatal hernia and coronary artery disease. He had a myocardial infarction in the past, which was complicated by congestive heart failure. Medications include: digoxin, furosemide, captopril, atenolol, prednisone, ranitidine and glyburide. Vital signs: P 59, BP 130/70, R 14, T36.9

What are your concerns about this patient?

\section{PREOPERATIVE MANAGEMENT}

Coronary disease 
- History: duration, symptoms, complications, myocardial infarction, heart failure

- Examination: full cardiovascular examination

- Tests: Would you order any tests? Why? ECG shows sinus rhythm, LBBB, relevance? Do you want any further tests? If so, which ones and why?

Medications:

Would you continue digoxin, captopril, atenolol, furosemide? Why, why not?

Rheumatoid arthritis (RA):

- How does history of RA affect your evaluation and management plan?

- History: duration, multisystem disease, severity, medications, steroid use.

- Tests: c-spine films

- Upon examination, patient can only open mouth $2 \mathrm{~cm}$. What if he opens $4 \mathrm{~cm}$ ?

- Perioperative steroid management

- Positioning

Hiatal hernia:

- Preoperative precautions, medications

Diabetes:

- History (onset adult vs juvenile, nephropathy, retinopathy, neuropathy)

- Physical

- Labs: glucose is 360, postpone case? Glycosylated $\mathrm{Hb}$

- Management of diabetic ketoacidosis or hyperosmolar state

- Perioperative management

Drug interactions: polypharmacy

\author{
ANESTHETIC PLAN AND INTRAOPERATIVE \\ MANAGEMENT \\ Monitors: art line, CVP ps PAC, TEE \\ - Do your monitoring choices change if GA vs \\ epidural? \\ Induction plan \\ Maintenance plan \\ Blood loss \\ Heat conservation \\ Positioning \\ PA catheter is placed \\ Critical incident: Bradycardia \\ Critical incident: Hypoxemia \\ Emergence \\ Postoperative disposition: ICU vs PACU \\ Decision to extubate.
}

\section{POSTOPERATIVE MANAGEMENT}

Pain control. Epidural management Hypothermia $\left(34.5^{\circ} \mathrm{C}\right)$
Stem case 2 (SC2): resident worksheet

A 47-yr-old obese female is scheduled for a pelvic exenteration (radical hysterectomy, oophorectomy, possible partial cystectomy and/or partial colectomy). She has a history of diabetes, hypertension, and asthma. Her medications include diltiazem, captopril, insulin, hydrochlorothiazide, cimetidine, and an albuterol inhaler. Her examination reveals P 68, BP $145 / 90$, R 14, T 37.0

\section{SC2: examiners grid}

A 47-yr-old obese female is scheduled for a pelvic exenteration (radical hysterectomy, oophorectomy, possible partial cystectomy and/or partial colectomy). She has a history of diabetes, hypertension, asthma, she has recently started treatment for reflux esophagitis. Her medications include diltiazem, captopril, insulin, hydrochlorothiazide, cimetidine and an albuterol inhaler. Her examination reveals P 68 , BP $145 / 90$, R $14, \mathrm{~T} 37.0$

\section{What are your concerns about this patient?}

\section{PREOPERATIVE MANAGEMENT}

Hypertension:

- History: duration, severity, medications, complications

- Examination: full cardiovascular examination Test:

Would you order any tests? Why? ECG shows LVH with "strain," relevance? Do you want any further tests? If so, which ones and why?

Would you continue diltiazem, captopril and hydrochlorothiazide; why, why not?

Asthma:

- History: duration, severity, medications, steroid use, hospitalization, recent wheezing

- Patient reports intermittent "chest tightness."

- Examination: end-expiratory wheezes are heard at the bases of both lungs.

- Cancel case?, Why? Why not?

- How to optimize patient preoperatively.

Obesity:

- How does obesity change your preoperative evaluation and anesthetic plan?

- What comorbid conditions are associated with obesity?

- Positioning

Reflux esophagitis:

- Preoperative precautions; medications

Diabetes:

- History: onset adult vs juvenile, nephropathy, 
retinopathy, neuropathy)

- Physical

- Tests: glycosylated Hb, glucose

- Ketoacidosis

- Perioperative management

Drug interactions: polypharmacy

\section{ANESTHETIC PLAN AND INTRAOPERATIVE MANAGEMENT}

Monitors: art line, CVP

Induction plan

Maintenance plan

Blood loss

Heat conservation

Positioning

Central line is placed

Critical incident: increased peak airway pressure.

Critical incident: hypotension

Emergence

Postoperative disposition ICU vs PACU

Decision to extubate

\section{POSTOPERATIVE}

Pain control

Hypothermia $\left(34.5^{\circ} \mathrm{C}\right)$

\section{Additional case 1 (ACl)}

A 60-yr-old man has a spinal anesthetic for transurethral prostatectomy (TURP). Six minutes after the administration of the spinal, his BP decreases from $120 / 60$ to $80 / 50$, and HR decreases from 85 to 45 . He has difficulty breathing and is becoming somnolent. What has happened? Pathophysiology? Management?_

\section{Additional case 2 (AC2)}

A 26-yr-old IV drug abuser requires an exploratory laparotomy. He has a history of hepatitis. What are your concerns? What anesthetic technique is the best? What agents to use? What are the risks?

\section{APPENDIX II}

The Oral Board Examiners Group were: Laurence Brownell MD, Professor, Department of Anesthesia, University of Manitoba, Winnipeg, Manitoba; Robert Friesen MD, Professor, Department of Anesthesia, University of Manitoba, Winnipeg; Joel B. Gunter MD, Professor, Department of Anesthesiology, University of Cincinnati, Cincinnati, Ohio; David Porembka DO, Professor, Department of Anesthesiology, University of Cincinnati, Cincinnati, Ohio; Heinz Reimer MD, Associate Professor, Department of Anesthesia, University of Manitoba, Winnipeg, Manitoba; David Rothenberg MD, Professor, Department of Anesthesiology, Rush Medical College, Chicago, Illinois. The Oral Board Examiners participated in the study by reviewing and scoring all the videotaped performances, and by reviewing the manuscript.

\section{References}

1 Eagle CJ, Martinean R, Hamilton K. The oral examination in anaesthetic resident evaluation. Can J Anaesth 1993; 40: 947-53.

2 Schubert A, Tetzlaff JE, Tan M, Ryckman JV, Mascha E. Consistency, inter-rater reliability, and validity of 441 consecutive mock oral examinations in anesthesiology: implications for use as a tool for assessment of residents. Anesthesiology 1999; 91: 288-98.

3 Kearney RA, Puchalski SA, Yang HY, Skakun EN. The inter-rater and intra-rater reliability of a new Canadian oral examination format in anesthesia is fair to good. Can J Anesth 2002; 49: 232-6.

4 Muzzin LJ, Hart L. Oral examinations. In: Neufeld VR, Norman GR (Eds). Assessing Clinical Competence. New York: Springer Publishing Co.; 1985: 71-93.

5 Burchard KW, Rowland-Morin PA, Coe NP, Garb JL. A surgery oral examination: interrater agreement and the influence of rater characteristics. Acad Med 1995; 70: 1044-6.

$6 \mathrm{Mc}$ Guire $\mathrm{CH}$. The oral examination as a measure of professional competence. J Med Educ 1966; 41: 26774.

7 Eagle C. Anaesthesia and education. Can J Anaesth 1992; 39: 158-65.

8 Linn BS, Zeppa R. Stress in junior medical students: relationship to personality and performance. J Med Educ 1984; 59: 7-12.

9 Schubert A, TetzlaffJA, Licina M, Mascha B, Smith MA. Organization of a comprehensive anesthesiology oral practice examination program: planning, structure, startup, administration, growth, and evaluation. J Clin Anesth 1999; 11: 504-18.

10 Newble DI, Swanson DB. Psychometric characteristics of the objective structured clinical examination. Med Educ 1988; 22: 325-34.

11 Colliver JA, Swartz MH, Robbs RS, Coben DS. Relationship between clinical competence and interpersonal and communication skills in standardized-patient assessment. Acad Med 1999; 74: 271-4. 